\title{
Trinta anos de Sistema Único de Saúde (SUS): uma transição necessária, mas insuficiente
}

\author{
Thirty years of history in the Brazilian Unified \\ National Health System (SUS): a necessary but \\ insufficient transition
}

Treinta años del Sistema Único de Salud (SUS):
una transición necesaria, pero insuficiente

\section{Resumo}

Considerando o acervo de conhecimentos sobre avanços e impasses do Sistema Único de Saúde (SUS), detalha-se, com base nas diferenças entre politicas voltadas à democratização e processos democratizantes, mudanças nos componentes público, filantrópico e privado que integram redes assistenciais e empresas de planos e seguros de saúde. Esse fio condutor permitiu interpelar afirmações laudatórias ou pejorativas sobre o SUS e caráter contemporâneo das relações entre o público e o privado a partir da mobilização de informações secundárias de fontes governamentais de órgãos dos poderes Executivo, Legislativo e Judiciário. Conclui-se que o setor privado e filantrópico-privado, eminentemente financeirizados, impuseram padrões para o uso do fundo público anti-democráticos e anti-democratizantes que embora não imponham ao obstáculo à determinados políticas públicas de ampliação do acesso, impedem a efetivação do SUS constitucional.

Sistema Único de Saúde; Atenção à Saúde; Política de Saúde
Ligia Bahia 1

doi: 10.1590/0102-311X00067218

\author{
L. Bahia \\ Departamento de Medicina Preventiva, Faculdade de Medicina, \\ Universidade Federal do Rio de Janeiro. \\ Praça Jorge Machado Moreira, Rio de Janeiro, RJ 21941-590, \\ Brasil. \\ ligiabahia@terra.com.br \\ 1 Faculdade de Medicina, Universidade Federal do Rio de \\ Janeiro, Rio de Janeiro, Brasil.
}


O Sistema Único de Saúde (SUS), uma das expressões sociais da transição democrática no Brasil, veio para ficar, mas a democratização da atenção à saúde permaneceu pendente. Embora, democracia e democratização tenham se imbricado historicamente, é relevante, para fins de debate, distinguir a natureza do regime político daquela relativa aos processos de inserção social nas diversas esferas que afetam a vida individual e coletiva. Essa perspectiva, tal como outras reflexões sobre o tema, busca reconhecer as interações entre sujeito e objeto ao considerar simultaneamente determinações estruturais e o caráter ativo e reflexivo das ações humanas. Assim, o fio condutor do texto é similar a de outras analises 1,2,3,4: houve mudanças democráticas. Além disso, é necessário evidenciar as linhas de contato entre estrutura e ação social que impulsionaram e impulsionam essas mudanças, bem como aquelas com sentido contrário, ou seja, que impulsionaram transformações antidemocratizantes.

As peças do repertório sobre o Sistema Único de Saúde (SUS) são diversificadas, têm sido devidamente atualizadas 5 e compartilham conhecimentos consolidados sobre a mobilização e as alianças que antecederam a inscrição dos direitos de seguridade social na Constituição Federal de 1988 e a implementação exitosa da reforma administrativa que extinguiu o Instituto Nacional de Assistência Médica da Previdência Social (Inamps) 6. Há também um relativo consenso sobre as razões que impediram a efetivação plena dos direitos à saúde. Alterações nos cenários internacionais (fim da polarização União Soviética-Estados Unidos, adesão generalizada aos cânones do neoliberalismo) e, no âmbito interno, políticas macroeconômicas restritivas e sociais focalizadas, além da herança (ou a dependência) da trajetória de um sistema privado, mitigaram (para alguns) ou interditaram (para outros) a consolidação de um sistema de saúde universal em um país capitalista periférico. Com exceção de argumentos laterais e mal-entendidos sobre as virtudes da "tática reformista", que carimbam erroneamente a própria assembleia nacional constituinte, como "transição pelo alto", prevalece uma acepção positiva sobre a natureza democrática do projeto do SUS.

A avaliação favorável ao SUS ao longo do tempo também foi incorporada por instituições especializadas que articulam interesses econômicos internacionais, como o Banco Mundial 7, e entidades de representação de empresas de saúde no Brasil 8. A atenção básica (saúde da família), financiada com recursos públicos, cresceu exponencialmente (o número de pessoas cadastradas em 2015, cerca de 116.600, é cinco vezes maior do que em 1998 (Departamento de Informática do SUS. Sistema de Informação de Atenção Básica - cadastramento familiar. http://tabnet.datasus.gov.br/cgi/deftohtm. exe?siab/cnv/SIABFbr.def, acessado em 04/Fev/2018). Por sua vez, o setor privado assistencial também se expandiu, e a Associação Nacional dos Hospitais Privados (Anahp) divulgou, em 2018, a abertura de mais de 3 mil leitos em hospitais privados. Reduziram-se, todavia, leitos públicos 9 . O SUS cresceu, mas não é único nem universal.

Houve uma mudança democrática, mas o projeto democratizante, especialmente o bloco que o formulou, perdeu potência para redefinir a matriz das políticas de saúde. Esse enfoque não é original, nem sequer inédito. Busca apenas desdobrar perguntas do acervo de conhecimentos, mediante abordagem não agregada dos serviços de saúde públicos, filantrópicos e privados e suas múltiplas mediações, sejam as decorrentes de determinações estruturais, sejam aquelas acionadas facultativamente por territórios e coalizões políticas.

O foco concentra-se nas alterações ao longo do tempo, na magnitude de cada componente, nas mudanças nos relacionamentos e nas agendas políticas das três modalidades assistenciais. Os pressupostos que orientam a adoção desse ângulo de observação incluem dois desdobramentos interligados entre si: evitar encarar o SUS apenas como uma totalidade constituída por componentes homogêneos e perceber o crescimento do setor privado e filantrópico e suas repercussões políticas e institucionais, bem como rebatimentos sobre interpretações da privatização no campo da saúde coletiva. Ou seja, o fio condutor questiona o ganha-ganha na saúde, como se a vitória do SUS pudesse ser obtida apenas pelo incremento do público e pudesse não priorizar estratégias efetivas de desprivatização.

Em outras palavras, considera-se que a expansão de empresas privadas assistenciais e de planos privados de saúde alterou a posição do tabuleiro e das peças do jogo político. Não há empate. Devese acrescentar que esse percurso não foi natural ou externo aos sujeitos envolvidos com a produção de conhecimentos e formulação de políticas de saúde. Essa hipótese, entretanto, não admite a versão "tudo sempre foi assim, a desigualdade é estrutural no capitalismo, ainda mais agora no capitalismo financeirizado, e sempre será, a não ser quando houver revolução”. Pelo contrário, o traço de normatividade subjacente a esse ponto de vista é que a crítica à realidade contém alternativas para superar 
o que existe. A exposição é inspirada em aportes da teoria crítica, que considera a necessidade de renovação permanente de diagnósticos, envolvendo tanto a crítica da sociedade injusta, assimétrica, quanto a análise das ideias que a legitimam, trazendo consigo perspectivas de transformações políticas, econômicas e sociais 10,11,12.

Os limites dessa argumentação incluem desde dificuldades de adequação de referenciais conceituais direcionados à compreensão do capitalismo e da sociedade a um recorte histórico específico até a omissão sobre heterogeneidades sociais e econômicas do país 13,14. Somadas à seleção arbitrária das informações utilizadas, essas falhas sobre produção de atividades, oferta de serviços, financiamento, decisões governamentais, posicionamentos políticos, conjugam-se ao longo do texto, conferindo-lhe um caráter necessariamente parcial e provisório.

\section{Público, filantrópico e privado: identidades trocadas}

Expressões muito frequentes, que reafirmam as dimensões grandiosas do SUS, são equivocadas. Algumas dessas expressões são as seguintes: "75\% da população só tem o SUS", "depende do SUS" ou, ainda, "o SUS, apesar de falhas, é o maior sistema de saúde universal do mundo". Outras expressões, igualmente equivocadas, reduzem seu potencial assistencial, como a de que "metade dos gastos com saúde é do SUS e metade é plano de saúde". Quem não está vinculado a plano privado pode buscar atendimento no SUS ou no setor privado. Parte das pessoas que têm cobertura de plano recorre à rede assistencial do SUS. Segundo a Pesquisa Nacional de Saúde (PNS) 2013, considerando quem não tem plano, 57,6\% declararam ter buscado atendimento no SUS, e 12,6\% pagaram pela assistência. Entre os vinculados a planos privados, $17,5 \%$ afirmaram terem sido atendidos em serviços públicos.

O SUS ampliou a oferta e o acesso à população, no entanto não pode ser considerado como sinônimo de rede estatal. Ademais, a "saúde suplementar" não pode ser compreendida como a totalidade do privado. As bases de informações sobre assistência à saúde do Ministério da Saúde e as da Agência Nacional de Saúde Suplementar (ANS) permitem uma aproximação da produção e das despesas pagas pelo governo e empresas de planos. Entretanto, não existem registros sobre atividades realizadas mediante pagamento direto apenas, nem sobre todas as fontes de financiamento do setor privado e filantrópico. "Regiões de sombra" tendem a suportar interpretações equivocadas sobre a primazia do privado. Caso a denominada renúncia fiscal divulgada oficialmente (pelo menos $\mathrm{R} \$ 25$ bilhões em 2015) 15 fosse considerada como gasto governamental e se buscassem estimativas mais realistas como deduções tributárias com pagamento de planos de saúde embutidas como custo operacional de empresas empregadoras, refinanciamento de dívidas (Refis), bem como créditos e empréstimos de entes governamentais - as proporções de despesas públicas (42\%) e privadas (58\%) 16 não seriam radicalmente alteradas, mas haveria maior precisão sobre valores de repasses públicos para o privado.

As informações sobre produção de serviços ambulatoriais e hospitalares disponíveis são incompletas, não incluem as atividades remuneradas pelas empresas de planos de saúde e o uso mediante desembolso direto e ainda deixam de registrar aquelas derivadas de arranjos locais (estados e municípios) que não formalizam a contratação de serviços privados 17 . O SUS não é "grande" ou "minúsculo". Não é o melhor, nem o pior. Não se compara com o sistema universal de um país populoso como Japão, nem em volume de atividades produzidas, nem em volume de recursos (despesas públicas no Japão representaram $84,1 \%$ do total de gastos em 2014) 18. Porém, é um sistema de saúde, e o Brasil não tem dois sistemas de saúde. Tem o SUS e um setor que comercializa planos de saúde e oferta serviços privados e filantrópicos, tanto na atenção ambulatorial quanto na hospitalar.

\section{Assistência ambulatorial}

Segundo a PNS, 71,2\% da população obtiveram atendimento para consulta médica em 2013, na rede SUS, e $23 \%$ das consultas foram pagas por empresas de planos privados (Departamento de Informática do SUS. Inquéritos e pesquisas. Pesquisa Nacional de Saúde - 2013: cobertura de plano de saúde. http://www2.datasus.gov.br/DATASUS/index.php?area=0208\&id=28247790, acessado em 04/Fev/2018). A assistência ambulatorial do SUS se expandiu entre 1995 e 2015. Com base nos dados da produção do SUS, o número total de procedimentos realizados passou de aproximadamente oito 
para 17 por habitante, e o setor público cresceu (realizou $80 \%$ das atividades em 1995 e $88 \%$ em 2015). Todavia, nesse período, os estabelecimentos públicos receberam relativamente menos recursos pelos serviços prestados que o setor privado, que ampliou sua participação de $21 \%$ para 23\%, e o filantrópico de $17 \%$ para $27 \%$. Observa-se uma especialização de setores para a produção de determinados procedimentos. Em 2015, o setor público realizou a maioria das consultas (75\%) e dos exames diagnósticos (59\%). O privado, por sua vez, foi responsável por $72 \%$ dos tratamentos de nefrologia, e o filantrópico por 66\% das quimioterapias (Departamento de Informática do SUS. Assistência à saúde: produção ambulatorial (SIA/SUS). http://www2.datasus.gov.br/DATASUS/index.php? area=0202\&id=19122, acessado em 04/Fev/2018).

Como uma parcela dos prestadores de serviços não estatais da rede SUS também atende a clientes de planos de saúde, é possível estimar números mais realistas a partir da soma das atividades ambulatoriais do SUS com as registradas pela assistência suplementar. Em 2015, a adição de 3,5 bilhões de procedimentos ambulatoriais produzidos e pagos por órgãos governamentais aos 1,2 bilhão de atividades (excluindo atendimentos odontológicos) remuneradas por empresas de planos 19 resultou na participação de $75 \%$ do SUS e de $25 \%$ da assistência suplementar. No entanto, essas proporções se invertem ao se considerarem os valores pagos. Entre o total de gastos realizados por ambas as alternativas de pagamento institucionalizado, 25\% foram do SUS e 75\% da assistência suplementar. O setor público predomina na produção total de atividades (65\%), mas recebeu apenas 10\% dos valores de remuneração, ao passo que o privado e o filantrópico, responsáveis por $35 \%$ dos atendimentos, 90\%. É preciso examinar com cautela essas informações, porque se referem a distintos setores, podendo haver inclusão ou não do pagamento de pessoal no cômputo das despesas relativas a produção de serviços.

Apesar da provável subestimação dos valores de pagamento (que são modificados frequentemente de "tabelas" próprias de estados e municípios), é plausível delinear duas tendências. A primeira refere-se ao incremento do setor público na produção de procedimentos de menor custo, participação residual dos contratos diretos com o setor privado e inclinação do filantrópico para atividades de maior valor de remuneração. A segunda configura-se pela divisão de atividades entre SUS e assistência suplementar, também modulada pelo procedimento, e não pela demanda. A especialização procedimento-setor impõe uma segmentação econômica e política que atravessa o SUS. Classificações dicotômicas - SUS e assistência suplementar (como se fossem conjuntos unitários sem intercessão) e aquelas baseadas na noção de baixa, média e alta complexidade tornam agentes e interesses sociais invisíveis.

Consequentemente, é questionável a ideia bastante difundida de uma atenção ambulatorial pública pouco atraente para os investidores em busca de altas taxas de retorno (uma "atenção básica com baixo custo e densidade tecnológica”, que se amplia, mas vai sendo deixada à margem das rotas da inovação-capitalização). O setor privado que realiza hemodiálise para o SUS aufere cerca de 10\% do total de gastos ambulatoriais, e o filantrópico, 7\%, com tratamentos oncológicos para pacientes não internados (Departamento de Informática do SUS. Assistência à saúde: produção ambulatorial (SIA/ SUS). http://www2.datasus.gov.br/DATASUS/index.php?area=0202\&id=19122, acessado em 04/ Fev/2018). Além disso, existe repasse de recursos das Organizações Sociais (OS) responsáveis por redes ou unidades ambulatoriais do SUS para a prestação de serviços, como exames diagnósticos, o que reforça o fluxo de recursos governamentais para o setor privado e filantrópico.

\section{Assistência hospitalar}

De acordo com a PNS, em 2013, a taxa de internação foi de 6\%, sendo 65,7\% remuneradas pelo SUS e 27,2\%, pelas empresas de planos (Departamento de Informática do SUS. Inquéritos e pesquisas. Pesquisa Nacional de Saúde - 2013: cobertura de plano de saúde. http://www2.datasus.gov.br/ DATASUS/index.php? area=0208\&id=28247790, acessado em 04/Fev/2018). Com base nos dados da produção, entre 1995 e 2015, houve redução do número de internações na rede SUS por habitantes (7,5\% para 5,3\%); a presença do setor privado recuou de $45 \%$ do total para $6 \%$, o filantrópico seguiu representando entre $33 \%$ e $34 \%$ e o público, antes responsável por $22 \%$, passou a produzir $43 \%$ do total (Departamento de Informática do SUS. Produção hospitalar (SIH/SUS). http://www2.datasus. gov.br/DATASUS/index.php?area=0202\&id=11633, acessado em 04/Fev/2018). Para determinados 
subgrupos de procedimentos, a distribuição entre setores da rede SUS é mais favorável ao filantrópico e ao privado: em 2015, entre os transplantes identificados por tipo de instituição, $49 \%$ foram realizados pelo setor filantrópico, $29 \%$ pelo público e $5 \%$ pelo privado 20 . Registros dos pagamentos de Autorização de Internação Hospitalar (AIH) na rede SUS evidenciam diferenciais entre a produção e a captação de recursos. Em 2015, o setor público realizou 43\% das internações e recebeu, em termos de repasses governamentais, apenas 37\%; já o filantrópico produziu $34 \%$ e auferiu $40 \%$. As variações nos valores pagos por internação se estendem para o interior do setor público. Os hospitais municipais receberam $\mathrm{R} \$ 680,00$ por internação, em média; os estaduais, $\mathrm{R} \$ 1.250,00$; os federais, $\mathrm{R} \$ 1.740,0020$.

As maiores disparidades nas atividades de internação referem-se aos distintos padrões de utilização e preços na rede SUS e na assistência suplementar. Em 2015, a rede SUS pagou 11 milhões de internações, e as empresas de planos privados, oito milhões. O valor médio de remuneração de uma internação para clientes de planos de saúde ( $\mathrm{R} \$ 6,5$ mil) é muito superior ao dos hospitais da rede SUS (R\$ 1,3 mil) 19. Considerando o montante da produção e dos valores pagos com internação pelo SUS (R\$ 13,8 bilhões - 21\%) e pelos planos privados (R \$ 52 bilhões - 79\%), a desproporção entre os setores aumenta. Por sua vez, a extensão do setor público fica reduzida ( $24 \%$ das internações e $20 \%$ dos valores pagos).

No interior da assistência suplementar, as faixas de preços são diferenciadas por modalidade da empresa (em 2015, por cada internação, as seguradoras pagaram, em média, R\$ 11 mil; as cooperativas médicas, $\mathrm{R} \$ 5 \mathrm{mil}$; as medicinas de grupo, $\mathrm{R} \$ 5,9 \mathrm{mil}$ ) 19 e por tipo de estabelecimento. Os 62 hospitais filiados à Anahp, que compreende estabelecimentos filantrópicos e privados (nos quais o valor médio das internações foi $\mathrm{R} \$ 21,8$ mil em 2015), produziram $11 \%$ das internações registradas pela ANS e receberam 36\% 20. Diferenças nas instalações físicas, densidade de equipamentos, gravidade dos pacientes e maior uso de recursos diagnósticos e terapêuticos, bem como valores superiores de remuneração de pessoal como fatores isolados ou combinados, dificilmente explicam esse amplo espectro de variação de preços.

Com base nas informações sobre produção de internações, a assistência hospitalar caracterizase: (a) pela presença de unidades públicas, hospitais filantrópico-privados e privados destinados ao atendimento de clientes de planos de saúde mais caros, concentrados na Região Sudeste; (b) por estabelecimentos privados e filantrópicos que atendem pacientes remunerados pelo SUS; (c) pelos planos privados (em proporções variadas) e por filantrópicos que internam pacientes remunerados pelo SUS. Preços díspares para serviços de saúde não são meros decalques das desigualdades sociais. Trata-se de uma estratificação complexa que envolve médicos-professores de universidades públicas, subsídios públicos para demanda e oferta, políticas públicas de créditos e estímulos para a diversificação de atividades. Além disso, os valores de remuneração de atividades para OS são definidos segundo critérios locais.

\section{O novo público, filantrópico e privado}

No setor público, a extensa e capilarizada rede de atenção básica, os programas de acesso a medicamentos, a extensa rede de hospitais municipais, as unidades de pronto-atendimento (UPAs), os centros de atenção psicossociais, entre outras estratégias assistenciais universais, não existiam antes, nem logo no início da implementação do SUS. A fisionomia do setor privado também foi alterada. O setor privado que se posicionou contra o SUS, no final dos anos 1980, era liderado por hospitais psiquiátricos, empresas de medicina de grupo e por algumas entidades de representação de médicos (que organizaram cooperativas médicas), naquele momento autofinanciadas. Os grandes grupos econômicos que atuam na comercialização de planos de saúde, farmácias e drogarias, hospitais, serviços de apoio diagnóstico são relativamente recentes. Houve, ainda, transformações no setor filantrópico. Atualmente existem três subsetores filantrópicos. O primeiro organiza-se em torno de hospitais gerais exclusivos para clientelas ricas e apresenta-se como um segmento descolado dos órgãos públicos. O segundo explicita demandas junto aos órgãos governamentais e também apoia proposições para ampliar o mercado de planos privados de menor preço. Por fim, o terceiro (especialmente voltado à oncologia) realiza atendimento universal e moderniza-se por meio de investimentos governamentais e políticas específicas. 
Entendimentos imprecisos sobre a Constituição de 1988 geram duas explicações questionáveis: a Constituição (e as negociações com a "direita") teria autorizado o crescimento do setor privado (que frequentemente baseia-se na ideia de que é a lei que determina a realidade), e o setor privado seria uma herança do regime militar (apoia-se, por vezes, no uso abusivo da categoria analítica de dependência de trajetória). Ambas as visões são irreverentes com a história. Os relatos de quem participou da redação do capítulo da saúde expõem o vigor da disputa entre o público e o privado: “...houve um barulhão, isso é estatizante, vai acabar com a iniciativa privada, não vai mais ter isso e aquilo” 21 (p. 108). Sem relativização, a aplicação automática da fórmula "o passado condena" condensa em si um problema cognitivo e político.

O público, o privado e o filantrópico contemporâneos conservam traços originais, mas não os mesmos de 1988. A atenção primária trouxe consigo agentes sociais, organizações, agendas e tensões. Além disso, de forma particular, acarretou também discordâncias em torno das recomendações internacionais sobre cobertura universal 22 e conflitos "para dentro", em virtude de sua ampla aceitação pelos empresários. Por um lado, foram criadas associações de agentes comunitários de saúde, muitas das quais a partir de escolas técnicas, fóruns oficiais que reúnem profissionais do programa Mais Médicos e um grupo autodenominado "médicos populares". Por outro, houve migração de médicos de família 23 para grandes empresas de planos de saúde e difusão de críticas acadêmicas ao "velho sanitarismo" 24. Quem trabalha no setor privado recomenda que a atenção especializada do SUS seja privada e contratada 25,26. Aqueles que atuam na rede pública estão engajados na defesa da Política Nacional de Atenção Básica (PNAB), realizam greves contra OS e propõem que os serviços públicos sejam estatais.

No mesmo sentido, do encontro de canais de expressão adequados a interesses particulares e gerais, grandes grupos empresariais (empresas de planos de saúde, indústria farmacêutica, indústria de equipamentos, distribuidores de insumos, hospitais filantrópicos e privados e laboratórios clínicos) se organizaram. As diligências empresariais para adoção de uma agenda menos paroquial têm sido razoavelmente bem sucedidas. Por exemplo, proposições como a autorização de empresas e capitais estrangeiros em todas as atividades assistenciais e planos privados populares adquiriram o estatuto de agenda pública.

As dimensões do setor público e do SUS são extensas em termos de produção de atividades, especialmente no âmbito ambulatorial, mas exíguas quanto à captação de recursos financeiros. Presumivelmente, a indefinição das fronteiras entre público, filantrópico e privado trava a plena implementação de políticas universais. Recentemente, parte dos hospitais privados e filantrópicos que possuem empresas diagnósticas acopladas ou integradas e que desempenham atribuições de OS passou a investir em cursos de Ensino Superior de enfermagem e medicina. São poucas as pesquisas dedicadas a compreender o novo setor privado e filantrópico. O conhecimento que circula sobre a privatização, inclusive na área de saúde coletiva, é hegemonicamente produzido por lobbies, alguns dos quais contam com sanitaristas entre seus quadros de consultores. A representação objetiva de grupos de pressão ou opinião e suas agendas, tais como associações de agentes comunitários de saúde, médicos de família e novas entidades de representação de interesses filantrópicos e privados, inclusive de OS, tem recebido pouca atenção dos pesquisadores.

\section{Interesses, alianças e conflitos: o SUS e os poderes da República}

Os trinta anos do SUS não são uma sucessão de eventos, governos e decisões de coalizões que conduziram e conduzem os blocos de poder. A política não se reduz à política institucional, aos partidos políticos e à relação formal entre os poderes Executivo, Legislativo e Judiciário. Ao contrário, envolve esferas formais e informais de debate, padrões de reconhecimento social e perspectivas concretas de desenvolvimento de projetos individuais e coletivos. Contudo, seria pretensioso demais para o escopo deste texto pretender discernir, no modelo de regulação social, os traços de transformação do sistema de saúde. Por outro lado, é possível evitar os embaraços decorrentes da justaposição do SUS ao Ministério da Saúde, ou de um SUS confinado aos limites do Ministério da Saúde acrescido de conselhos de secretários estaduais e municipais. As políticas para a saúde não são geradas apenas nas entranhas da pasta especifica da área. Uma pequena abertura do foco institucional e político contribui 
para evidenciar o enraizamento das políticas favoráveis e contrárias ao SUS em diversas instâncias de articulação de demandas e agendas.

Proposições originadas na Presidência da República, no período 2012 a 2016, podem ser agrupadas em duas categorias: medidas com caráter sistêmico e medidas voltadas a problemas particulares. O primeiro grupo está representado por três leis: (a) Lei Complementar no 141 de 2012, que restringiu o orçamento da saúde; (b) Lei no 12.871 de 2013, com natureza expansionista, mediante alteração da escala da atenção básica e formação dos médicos, que instituiu o programa Mais Médicos; (c) Lei no 13.097 de 2015 (uma proposição em meio a diversos assuntos), que alterou a Lei Orgânica da Saúde, permitindo que empresas estrangeiras participem, inclusive como controladoras, dos empreendimentos de assistência à saúde. $\mathrm{O}$ segundo subconjunto de normas legais inclui estratégias para instituir ou respaldar programas para controle de uso de drogas e tratamento de câncer. A decisão de combater o uso do crack foi objeto da Lei no 12.681 de 2012, que instituiu o Sistema Nacional de Informações de Segurança Pública, Prisionais e sobre Drogas, com a finalidade, entre outras, de "enfrentamento do tráfico de crack e outras drogas ilícitas". O atendimento tempestivo aos pacientes com câncer estimulou a Lei no 12.732 de 2012, que fixou prazo para tratamento de pacientes com diagnóstico de neoplasia, e o Programa Nacional de Apoio à Atenção Oncológica (Pronon), Lei no 12.715 de 2012, que concedeu incentivos fiscais para instituições privadas e filantrópicas (inclusive OS).

Após o impedimento da Presidente Dilma Rousseff, as despesas com saúde e o SUS, bem como com as demais áreas sociais, especialmente a Previdência Social, foram oficialmente julgadas como as causas do desequilíbrio fiscal. O hiperajuste fiscal adquiriu estatuto legal com a aprovação de Emenda Constitucional (EC) 95 de 2016, que congelou despesas primárias por vinte anos. O Ministro da Saúde Ricardo Barros respaldou proposições contencionistas:

"Não estamos em um nivel de desenvolvimento econômico que nos permita garantir esses direitos por conta do Estado (...) quanto mais gente puder ter planos, melhor, porque vai ter atendimento patrocinado por eles mesmos, o que alivia o custo do governo..." 27.

Com isso, criou-se um grupo de trabalho ministerial com participação de representantes das empresas para formular um projeto de planos populares 28 . Posteriormente, foi promulgada uma medida ${ }^{29}$, baseada na suposição de eficiência, e não em prioridades sanitárias, que desonera a União de sua atribuição de planejamento e coordenação compartilhada do SUS ao redefinir critérios para transferência de recursos para estados e municípios. O caráter regressivo do governo não eleito afetou ainda ações relativas a demandas identitárias e a segmentos populacionais minoritários.

Iniciativas adotadas por outros ministérios do Poder Executivo, entre os quais o Ministério do Planejamento, Fazenda e Justiça, tiveram sentido contrário à expansão do setor público e do SUS. A Portaria do Ministério do Planejamento no 3 de 2013 previu "universalidade e equidade" exclusiva para servidores públicos federais. A receita federal, que em 2009 estendeu as deduções com despesas médicas para incorporar cirurgias plásticas estéticas, concedeu mais um estímulo fiscal relativo a despesas médicas no exterior (Instrução Normativa RFB no 1.500, 2014). O Conselho de Defesa Econômica (CADE), órgão do Ministério da Justiça, cuja atribuição é preservar a concorrência (que tem aprovado acriticamente conglomerações empresarias de empresas de planos, laboratórios clínicos, farmácias e drogarias e hospitais), tem avaliado o SUS, em julgamentos e em documentos, como um projeto fracassado e relativamente insignificante.

"Implementado em 1990, o SUS deveria ser responsável, segundo a Constituição Federal de 1988, por assegurar o livre acesso aos serviços de saúde como um direito universal a cada um dos cidadãos brasileiros. No entanto, embora a ideia de garantir livre acesso à saúde ter sido inicialmente um grande sucesso, não demorou muito até que o programa de saúde pública revelasse algumas falhas (longas listas de espera, ausência de médicos, baixa qualidade dos serviços) e se mostrasse insustentável, diante da dimensão da população brasileira. (...) Atualmente, a infraestrutura de saúde é praticamente toda de origem privada" 30 (p. 5).

O Banco Nacional de Desenvolvimento Econômico e Social (BNDES) mantém linhas de financiamento para serviços assistenciais públicos, filantrópicos e privados e indústrias de saúde. De acordo com o relatório de sustentabilidade, de 2007 a 2014, a instituição apoiou a abertura de 5,6 mil leitos (somados públicos e filantrópicos) e 3 mil (35\% do total) privados 31. Entre 2002 e 2017, a maior parte dos recursos foi destinada para reformas, ampliação e construção de hospitais filantrópico-privados (31\%) e privados (26\%). As unidades públicas receberam 15,5\% dos recursos, ao passo que os filantrópicos que integram a rede do SUS, $11,2 \%$. O restante dos recursos foi destinado para a indústria e para 
laboratórios públicos (Fundação Oswaldo Cruz e Instituto Butantan), empresas de planos de saúde, fundações de hospitais públicos e universitários, laboratórios privados de análises clínicas e construção de um hospital em parceria público-privada (BNDES. Consulta às operações diretas e indiretas não automáticas. Contratações por sub-setor agrupado. https://www.bndes.gov.br/wps/portal/site/ home/transparencia/consulta-operacoes-bndes/, acessado em 20/Mar/2018).

Assim como o BNDES, a Caixa Econômica Federal e o Banco do Brasil dispõem de linhas específicas de crédito para instituições hospitalares filantrópicas e privadas. Órgãos e autoridades do Poder Executivo não compartilham a mesma compreensão sobre o SUS. É importante constatar, em diversos ministérios da área econômica e de planejamento em bancos públicos, a presença de servidores públicos concursados que planejam e implementam ações para a expansão da rede assistencial privada. Certamente, não é possível separar totalmente as iniciativas do Poder Executivo daquelas que tiveram como arena principal o Poder Legislativo, como ocorreu com a autorização para o uso da fosfoetanolamina (Lei $n^{\circ} 13.269$ de 2016), cujo projeto original foi apoiado por parlamentares de diversos partidos (PT, PMDB, PSDB, DEM, PSB, entre outros). Entretanto, a noção do Parlamento como o único ou o principal locus do retrocesso não adere totalmente aos processos mais recentes de mudança no sistema assistencial. O Poder Executivo concede suporte político e financeiro aos setores filantrópico e privado e a empresas de planos de saúde.

No Poder Legislativo federal, os debates sobre SUS e setor privado de saúde são permanentes. Reivindicações de profissionais de saúde, grupos de pacientes de patologias específicas, Organizações Não-governamentais (ONGs) que defendem determinados procedimentos ou medicamentos, entidades de defesa do consumidor, conselhos de saúde, representantes de empresas e empresários, entidades sem fins lucrativos, pesquisadores, bem como integrantes do Poder Executivo das três esferas de governo, transitam em audiências públicas, em comissões especiais e em gabinetes de parlamentares. Assuntos que polarizaram as legislaturas pós-Constituição de 1988, entre outros, foram a legalização do aborto, a convenção-quadro do tabaco, a regulação da propaganda de alimentos e a proibição do uso de anorexígenos 32 .

Demandas específicas e tentativas de agrupá-las na Câmara de Deputados encontraram canal de expressão nas frentes parlamentares. Entre as 319 frentes organizadas pela legislatura 2015-2018, trinta estão diretamente relacionadas com assistência à saúde, produção e distribuição de insumos e medicamentos. A maior parte dessas frentes está dedicada a temas como doenças ou condições relacionadas com ciclo de vida, ou etnia e gênero, ou área/profissão de saúde. O segundo subgrupo volta-se a temas sobre assistência à saúde, rede assistencial do SUS e programas/políticas universais. A mais conhecida e antiga (instituída em 1993) é a Frente Parlamentar da Saúde, que adquiriu maior visibilidade em face das demandas pela regulamentação da EC 29. Em 2015, foram registradas duas frentes: defesa do sistema nacional de auditoria do SUS e doação e captação de órgãos para transplantes. Em 2016, foi a vez da reforma psiquiátrica e da defesa do SUS. Por fim, em 2017, deu-se a frente de defesa da construção do hospital do câncer do Grupo Hospitalar Conceição 33.

Além das frentes parlamentares, entre 2015 e 2017, duas comissões especiais tiveram como tema central o percentual mínimo para a saúde (encerrada em 2016) e a revisão da legislação sobre regulamentação de planos privados de saúde, que ainda está em funcionamento. A primeira manteve diálogo permanente com o Conselho Nacional de Saúde (CNS) e entidades alinhadas com a efetivação do SUS. A segunda convocou doze representantes das empresas de planos de saúde, três de entidades profissionais, dois pesquisadores, um de entidade de defesa do consumidor e um da ANS. Parlamentares de diversos partidos participaram de ambas. Discursos e posicionamentos de deputados podem ser simultaneamente laudatórios ao SUS e discordantes de seus princípios. Para o deputado Nelson Marquezelli (PTB de São Paulo):

"O SUS é o maior programa de saúde do planeta e não pode retroceder. Todos precisam trabalhar e contribuir para a sustentabilidade do sistema. O sistema deveria ser minimamente remunerado pelo usuário, o que contribuiria para reduzir o descontrole da demanda. É preciso ter coragem para controlar a demanda" 34.

Providências para assegurar atendimento a pacientes do SUS, inclusive por meio de emendas ao orçamento, estimular a privatização e simultaneamente barganhar cargos no Poder Executivo são disseminadas e notórias. Em 2017, o senador Eunício de Oliveira (PMDB do Ceará) tornou-se conhecido como "o dono da ANS" 35, e o partido Podemos notabilizou-se por retomar a Fundação Nacional de Saúde (Funasa) 36. A atuação de parlamentares, à primeira vista incongruente, faculta práticas que 
permitem solucionar problemas de acesso ao SUS para eleitores das bases e mantém sintonia com inclinações pragmáticas ou ideológicas privatizantes para o diálogo com empresários.

A saúde tem sido um tema frequente na agenda de trabalho do Poder Judiciário. Examinando apenas parte das decisões do Supremo Tribunal Federal (STF), por meio de consulta ao Informativo do STF, observa-se uma diversidade de temas. Entre 2015 e 2018, as principais decisões da corte constitucional incidentes direta ou indiretamente sobre assistência à saúde foram as seguintes: banimento do amianto, julgamento favorável a demandas de medicamentos não incorporados pelo SUS, proibição do atendimento diferenciado para pacientes que pagariam por acomodações individuais, permissão para o reingresso no plano da Geap de servidores do Instituto Nacional de Colonização e Reforma Agrária (Incra) e constitucionalidade das OS. Além dessas controvérsias, ficou estabelecida a legitimidade da cobrança do imposto sobre serviços (ISS) de empresas de planos de saúde, bem como a constitucionalidade do ressarcimento ao SUS e da exigência de documentos que comprovem negação de coberturas para clientes de planos privados de saúde. A Agência Nacional de Vigilância Sanitária (Anvisa) foi simultaneamente presumida como autoridade sanitária responsável pelo registro de medicamentos (na argumentação utilizada para suspender a lei que autorizou o uso da fosfoetanolamina) e inadequada para proibir aditivos ao tabaco (STF. Pesquisa de jurisprudência: informativo por temas. http://www.stf.jus.br/portal/cms/verTexto.asp?servico=publicacaoInformativoTema, acessado em 04/Fev/2018).

O elenco parcial de questionamentos sobre a assistência à saúde direcionados ao STF sinaliza a existência de divergências sobre fundamentos básicos do direito à saúde. Embora a Constituição de 1988 seja necessariamente aludida, as polêmicas judiciais englobam a tributação de empresas, a cobrança a pacientes em instituições contratadas por secretarias de saúde, o papel de organizações de planos de saúde para servidores públicos e a legitimidade sanitária do Ministério da Saúde e da Anvisa para definir diretrizes assistenciais. Assinala-se ainda que os interesses empresariais, concernentes a tributação, medicamentos e ressarcimento ao SUS, ocuparam parcela significativa da pauta do STF. A morosidade das decisões sobre determinadas polêmicas, como OS e ressarcimento ao SUS, possivelmente sinalizaram assentimento ao modus operandi predatório de grupos empresariais.

Recentes decisões do STF sobre a importância de impedir redução do financiamento da União para a saúde, mediante suspensão de artigos da legislação sobre orçamento impositivo em 2017, e obrigatoriedade do ressarcimento ao SUS, em 2018, parecem decorrer de interpretações mais rigorosas do texto constitucional. Porém, a movimentação de empresas e de grupos empresariais nos tribunais tem sido permanente. Por um lado, buscam impedir o que denominam "judicialização contra o mutualismo", ou seja, pretendem impedir o acesso de clientes de planos de saúde à justiça. Por outro, apresentam-se como organizações de relevância pública e solicitam isenções tributárias, além de questionar e postergar o pagamento de impostos devidos.

\section{Da centro-esquerda para o ceticismo e pragmatismo e centrão: repercussões sobre o SUS}

A compreensão sobre o SUS pela coalizão política que confere suporte às atuais instituições governamentais é radicalmente distinta daquela consolidada durante o processo de debates e aprovação da Constituição de 1988. O bloco de centro-esquerda, conformado pelo PMDB autêntico, PCB, PT, PC do B e movimentos sociais progressistas, teve oposição aguerrida do denominado "centrão", grupo suprapartidário integrado por parlamentares conservadores do PFL, do PMDB, do PDS e do PTB, entre outros. Em 1987, o jornal O Estado de São Paulo publicou matéria intitulada Estatização Degrada Medicina Brasileira, sintetizando críticas ao SUS e às lideranças do movimento sanitário 37.

"No texto já elaborado da futura Constituição, redigido sob a pressão da 'canhota' parlamentar, inclusive com apoio de certas autoridades do governo, está dito que 'a saúde é um direito universal', tornando-se obrigação a ser completamente assegurada pelos poderes constituídos. (...) Célebres defensores da 'medicina de massa' capitaneados por médicos e funcionários de orientação marxista, tipo Hesio Cordeiro e outros membros dos 'partidões' manipulam a seu bel-prazer o dinheiro do contribuinte que espera miseravelmente nas filas do Ministério da Previdência Social. (...) Aliás, diga-se de passagem, que os membros da Academia Nacional de Medicina, considerados os expoentes maiores da cultura médica brasileira, até o advento da novíssima república, 
desconheciam por completo 'cientistas' como o atual secretário de saúde do Rio e também presidente da Fundação Oswaldo Cruz, Sergio Arouca, em cujo currículo consta apenas como grandes feitos de sapiência o fato de ter organizado o sistema médico da Nicarágua, na época em que andou foragido da ditadura militar no Brasil..." 37.

Atualmente, as controvérsias sobre a Constituição de 1988 têm outro teor. Há quem assinale o pequeno grau de permanência e estabilidade da carta, exigindo que os sucessivos governos se dediquem a modificá-la 38 e a considerem referência partilhada por todas as forças políticas do país 39. No que se refere especificamente à saúde, o avanço do texto constitucional é quase consensualmente reconhecido. Contudo, o reconhecimento sobre a rearticulação das forças políticas conservadoras logo após sua promulgação e as consequências para a implementação do SUS não gozam de igual prestígio. Quando a ênfase recai exclusivamente na conquista legal, a identificação das regras do jogo político fica prejudicada. O protagonismo do Legislativo na definição das diretrizes sobre o SUS foi breve. O Poder Executivo passou a concentrar as decisões ganhadoras e perdedoras, assim como a direcionalidade das reformas administrativas e regulatórias.

Durante o Governo José Sarney, em 1988, a agenda de reformas da Seguridade Social foi freada pela substituição do Ministro da Previdência Renato Archer (uma liderança progressista) por Jader Barbalho, e de Hesio Cordeiro pelo médico particular do então presidente. Logo depois, o discurso de posse do Presidente Fernando Collor de Mello em 1990 priorizou políticas sociais assistencialistas.

"O Estado deve ser apto, permanentemente apto, a garantir o acesso das pessoas de baixa renda a determinados bens vitais. Deve prover o acesso à moradia, à alimentação, à saúde, à educação e ao transporte coletivo a quantos deles dependam para alcançar ou manter uma existência digna, num contexto de iguais oportunidades - pois outra coisa não é a justiça, entendida como dinâmica social da liberdade de todos e para todos" 40 (grifos meus).

Fernando Henrique Cardoso, no CNS em 1997, reafirmou a orientação da política de saúde para pobres: "Eu acho que os que dispõem de recursos não têm por que apelar para a gratuidade da saúde, se eles têm condições de pagar um seguro a ser utilizado. Não se pode, em nome de um valor abstrato, na prática, prejudicar a maioria mais carente e mais pobre. Isso é hipocrisia, não é crença em nenhum valor defensável do ponto de vista filosófico" 41 (grifos meus).

Apesar da inclinação neoliberal assumida pelas coalizões políticas até 2003, houve avanços na implementação do SUS, mas não foram lineares. A convivência paradoxal entre reforma administrativa resultante da extinção do Inamps, instabilidade institucional (troca de ministros e equipes) e estabilidade no âmbito econômico (ajuste fiscal, subfinanciamento da saúde e disputa dos movimentos sociais por parcelas do fundo público) distanciaram o SUS da agenda da Reforma Sanitária 1.

As análises sobre as políticas de saúde nos governos do PT ainda são embrionárias. Todavia, é impossível ignorar que quase metade (13) dos trinta anos de SUS transcorreram durante governos nucleados por um partido de matriz popular. Talvez a primeira fase do Governo Luís Inácio Lula da Silva (2003-2005), uma conjugação de políticas heterodoxas, como recuperação do valor do salário mínimo, com acesso a crédito e ao sistema bancário, condizentes com a ortodoxia fiscal, até o mensalão, tenha sido a mais relevante para a saúde (ou pelo menos para as conjecturas deste texto). O primeiro Ministério da Saúde, composto eminentemente por quadros sanitaristas do PT e por alguns aliados, inclusive nas agências reguladoras (exceto diretoria indicada por entidades empresariais), teve duração curta.

É possível supor que a fissura na equipe da saúde durante o primeiro mandato do PT, conjugada com movimentos favoráveis a fundos de pensão e empresas setoriais, especialmente dos ministros da Casa Civil e da Fazenda 42, tenha impulsionado uma aproximação de lideranças do setor privado e filantrópico ao núcleo dirigente do governo, uma vez que antes orbitavam em torno do PSDB-PFL -PTB. A partir de 2005, quando foi selada a aliança do PT com o PMDB e o empresariado nacional (empreiteiras, grandes empresas industriais, mineradoras e de serviços), os Ministros da Saúde foram sucessivamente os sanitaristas Saraiva Felipe, Agenor Álvares e José Gomes Temporão, que procuraram alocar profissionais competentes em cargos estratégicos, mas as pressões de partidos da base aliada intermediadas por grupos econômicos se intensificaram.

Impasses normativos que supostamente seriam equacionados durante os mandatos do PT, como o ressarcimento ao SUS, exigência de coberturas contratuais, cobrança de multas, não foram resolvidos e ficaram obsoletos perante a operacionalização de novos instrumentos jurídico-legais e financeiros de alavancagem do mercado. Em sentido diverso ao da "ocupação" sanitarista do Ministério da Saúde, 
em 2010, foi empossado como presidente da ANS um dirigente de empresa de plano de saúde, fato que eventualmente passou por "mal menor" e até positivo (em função do conhecimento empresarial para dirigir uma agência reguladora).

A noção de defesa da governabilidade e suas distintas facetas pragmáticas e operacionais repercutiram na saúde. Tanto a acepção de aliança provisória (até constituir maioria no parlamento) e seus desdobramentos em termos de vinculação de políticas sociais às eleitorais, quanto a noção de que a expansão das coberturas do SUS autorizaria consentir, ainda que passivamente, à privatização se descolaram de referenciais sobre o processo saúde-doença-cuidado. A relação orgânica com os interesses populares (que permitiu a aprovação do capítulo da saúde na Constituição de 1988) foi preservada e ampliada, mas a convicção de alguns a respeito da inevitabilidade e até virtuosidade da presença de grandes grupos econômicos setoriais isentou-os ou autorizou-lhes adiar sine die a orientação das políticas em direção ao fortalecimento do componente público do SUS.

Durante o primeiro e início do segundo mandato de Dilma Rousseff, a fórmula PT na saúde foi parcialmente retomada. Quadros mais jovens (da geração posterior àquela que esteve à frente da luta contra o regime militar) assumiram cargos de direção no Ministério da Saúde. No entanto, os setores empresariais continuaram influenciando a indicação de seus pares para órgãos públicos e ocuparam novos espaços: organizaram reuniões com a Presidência da República para apresentar ousados projetos para a saúde do país. Nas eleições de 2014, o movimento sanitário, que tinha a primazia da formulação de alternativas para a saúde, foi sobrepassado pela divulgação de encontro da Presidência da República e de ministros da área econômica para exposição de teses empresariais sobre as vantagens de um mercado subsidiado abrangente e vigoroso. Em 2015, o retorno ao expediente de recorrer ao PMDB para ampliar as bases governamentais dispensou a mediação de sanitaristas.

O golpe parlamentar de 2016, efetuado pela maioria do PMDB, PSDB e outros partidos antes integrantes da base governamental, trouxe para a saúde um "centrão" turbinado, nucleado por parlamentares conservadores e secretários de saúde que vêm desfraldando bandeiras contra a Constituição de 1988: o SUS e seus programas voltados à proteção de etnias/raças, famílias plurais, LGBT, feministas, ações antimanicomiais, bem como os critérios de repasse dos recursos federais. Conselho Nacional de Secretários de Saúde (Conass) e Conselho Nacional de Secretarias Municipais de Saúde (Conasems), que estiveram perfilados com movimentos sociais em torno de mais recursos para a saúde, depois do resultado desfavorável ao PT nas eleições municipais, deslocaram-se para o polo mais conservador do espectro político.

Para uma análise longitudinal, os projetos societários de maior alcance podem ser balizadores temporais adequados. Nessa trilha, é importante situar, em primeiro lugar, a desestruturação do então PCB, que esteve à frente da campanha pelas Diretas Já, pela Assembleia Nacional Constituinte e pela Reforma Sanitária, mas que, por razões internas e internacionais, não seguiu acompanhando seus desenvolvimentos. A seguir, as outras marcas seriam os projetos de desregulamentação e focalização de políticas sociais do PSDB, que deixaram traços permanentes nas políticas de saúde. Acrescentemse, durante os governos do PT (sem desconsiderar importantes programas de expansão de coberturas, como o farmácia popular, UPAs, Serviço de Atendimento Móvel de Urgência - SAMU e Mais Médicos), o projeto de articulação de políticas sociais, com a criação do Ministério das Cidades, e a tentativa do Mais Saúde de operacionalizar um plano de expansão do SUS mediante uso dos recursos da Contribuição Provisória sobre Movimentação Financeira (CPMF).

Tais projetos de reformas democráticas na saúde, quer os orientados pelas teses gramscianas do PCB, quer aqueles que emergiram das experiências de participação social e compromisso socialista do PT, esgotaram-se, ficaram para trás ou necessitam de profunda atualização. Parte das forças políticas que os formularam e novos movimentos sociais estão às voltas com as ofensivas da coalizão de centro-direita e deparam-se com imensas dificuldades para reconstruir pontes entre a sociedade e os sistemas de representação política. A polarização política pré e pós-golpe atingiu fortemente a saúde, inicialmente quando entidades médicas se posicionaram contra o programa Mais Médicos e depois com a oposição feroz de partidos políticos e movimentos sociais conservadores a tudo que aluda a direitos humanos (inclusive saúde em seu conceito amplo). $\mathrm{O}$ atual panorama de aglutinação de forças políticas requer redobrar esforços teóricos para compreender os rebatimentos da crise mundial e os limites para a compatibilidade entre capitalismo financeirizado e democracia 43 , singularidades das relações entre desenvolvimento econômico e direitos sociais no Brasil e o empresariamento da saúde 
nos anos 2000. Pragmatismo e ceticismo impedem a realização de diagnósticos realistas, mesmo que embalados na apologia a um SUS que se "defende", mas que não se "usa" (ou, ainda pior, que se diz usar, porque a água é tratada e os medicamentos são controlados, como se nos Estados Unidos não houvesse o Centers for Disease Control and Prevention - CDC e o U.S. Food and Drug Administration - FDA).

\section{Considerações finais}

A democracia trouxe para o Brasil imensos avanços, especialmente durante o período em que o desenvolvimento econômico foi acompanhado por diminuição das desigualdades sociais, ainda que a velocidade e a amplitude das mudanças possam ser questionadas. Também na saúde houve notáveis avanços relativos à alteração dos padrões de mortalidade e morbidade, bem como ampliação do acesso ao SUS e da oferta de serviços ligados a esse sistema. O SUS emergiu de uma crise do sistema privatizado hegemonizado pelo Inamps, no final da ditadura militar. O bloco de poder privatizante dos anos 1970 e 1980 liderado pela Federação Brasileira de Hospitais e integrado por lideranças de empresas de medicina de grupo e cooperativas médicas autofinanciadas se desagregou. Entretanto, ao longo dos trinta anos do SUS, não houve uma coalizão política alternativa estável ou capaz de estabelecer regras ou de reger a disputa política.

Setores privados e filantrópico-privados eminentemente financeirizados impuseram padrões para o uso do fundo público antidemocrático e anti-SUS. Atribuir essa situação apenas à estrutura (as determinações de longa duração) ou a ações intencionais ou impensadas (em contextos imediatos) reduz o alcance do enfoque de uma situação complexa. Não foi somente o passado longínquo de escravidão, de desigualdades estruturais, de inserção dependente na economia mundial e nem o período recente, no qual houve ascensão dos segmentos de renda C e D a melhores condições de trabalho e vida, que nos condenou ao crescimento exponencial do mercado de planos privados. Tampouco se poderia identificar o culpado em determinado partido político, poder republicano ou autoridade governamental, ou mesmo em sindicatos de trabalhadores, em entidades médicas ou ainda na "sociedade", pela segmentação e reestratificação da assistência à saúde.

Estamos diante de uma feroz competição política entre público e privado por recursos materiais e simbólicos, apresentada candidamente como "desoneração do SUS", que atravessa o sistema político. Sem análises apuradas, as disputas tendem a permanecer silenciosas e pouco compreendidas. Mudanças antidemocratizantes na saúde, com características distintas e possivelmente não cumulativas, ocorreram durante os governos do PSDB e do PT. A presença e a expansão de atividades empresariais na assistência à saúde têm sido alternativamente aludidas à inexorável força do capitalismo ou à incompletude do SUS. Posicionar-se como observador externo das políticas de saúde inibe a disputa concreta de poder e projetos alternativos.

Forças políticas de centro-direita e os empresários do setor de assistência à saúde, sem apoio de movimentos sociais, oferecem a ampliação de seus mercados como projeto para o sistema de saúde, na prática um impiedoso modelo de segregação social. Contudo, a população e as parcelas organizadas da sociedade não parecem dispostas a aceitar a subtração de direitos sociais. Por exemplo, a reforma da Previdência Social, justamente a principal diretriz da "ponte para o futuro", não foi adiante. Analogamente, nada indica que o SUS poderá ser descartado ou que exista apoio popular ao empresariamento da saúde. Pelo contrário, ao longo dos últimos trinta anos, foi consolidada a ideia de que a resposta para os problemas de saúde no Brasil é o SUS. No entanto, nesse mesmo período, cristalizaram-se visões negativas sobre a ineficiência, a má gerência de recursos, o descaso e a despersonalização do atendimento no setor público. Não é casual que as soluções governamentais e empresariais para o SUS, apresentadas no auge do sucesso do Mais Médicos, tenham gravitado em torno do credenciamento de especialistas. Exatamente quando grupos econômicos investiram, ironicamente, na expansão de oferta própria de clínicas populares, surgiu uma alternativa mais "sustentável" (com médicos sem contrato, recebendo apenas por produtividade ou como pessoa jurídica).

A crise política e econômica tem sido entendida por empresários e por outros segmentos sociais como exclusivamente de natureza fiscal. Com investimentos públicos subordinados à diminuição dos gastos correntes, o rent-seeking "no atacado" entrou no radar dos empresários setoriais. A estratégia 
"integracionista" público-privada deriva desse frisson especulativo. Porém, as atividades de empresas de planos de saúde, hospitais, farmácias e drogarias e outros ramos de negócios setoriais não resolvem problemas e necessidades de saúde e nem produzem impacto em termos de evolução tecnológica e produtiva.

Nesse momento, em que se conclui este texto com o objetivo de debater os trinta anos do SUS, nada é muito claro. As respostas às interrogações sobre tendências de aglutinação de frentes de esquerda ou reafirmação das alianças com partidos progressistas com o PMDB admitem multivariações. As poucas certezas orbitam em torno das constatações sobre os limites para transformações sociais. Logo, para o movimento sanitário, a elaboração de projetos e o delineamento de estratégias e táticas são inescapáveis. Além das reformas para a justiça tributária e o equacionamento distributivo do déficit fiscal, as questões relativas aos direitos individuais, o racismo, as etnias, a igualdade de gênero, o modo de produção capitalista e predatório, bem como a inserção do país na divisão internacional do trabalho e geopolítica global, são temas prioritários. Esse conjunto de problemas/temas tem comparecido assiduamente nos fóruns de debates da saúde coletiva como um catálogo meio desconjuntado de ideias. A articulação entre um padrão de desenvolvimento democrático e democratizante (macroeconomia expansiva, política industrial e promoção da indústria nacional em atividades intensivas, que não aceite como inevitável a desigualdade, a devastação ambiental e um sistema político estruturalmente corrupto) permanece em estágio probatório, não se expressou ainda como projeto. Para refletir sobre democracia, Constituição de 1988 e SUS, buscou-se guarida na teoria crítica, na afirmação de Marx 44 (p. 25) de que "os homens fazem sua história, mas não a fazem como querem; não a fazem sob circunstâncias de sua escolha....

O par conceitual democracia e democratização é um atalho operacional, mas coordenadas casualmente definidas não conduzem às grandes tradições estruturalistas ou interpretativas das ciências sociais. Assim, as restrições teórico-conceituais conjugadas a sucessivas seleções intencionais de informações requerem cautela com generalizações dedutivamente relacionadas, especialmente quando associadas como proposição explanatória. A tentativa foi evitar que o objeto SUS e um sujeito, nós sanitaristas, tornassem-se abstratos e evaporassem, em um contexto que requer a reunião de convicções e vontades.

\section{Referências}

1. Paim JS. Reforma sanitária brasileira: contribuição para a compreensão e crítica. Salvador: EDUFBA/Rio de Janeiro: Editora Fiocruz; 2008.

2. Cordeiro H. Sistema Único de Saúde. Rio de Janeiro: Ayuri; 1991.

3. Costa AM, Noronha JC, Noronha GS. Barreiras ao universalismo do sistema de saúde brasileiro. In: Tetelboin C, Laurell AC, organizadores. Por el derecho universal a la salud: una agenda latinoamericana de análisis y lucha. Buenos Aires: Consejo Latinoamericano de Ciencias Sociales; 2015. p. 17-39.
4. Levcovitz E, Machado CV, Lima LD. Política de saúde nos anos 90: relações intergovernamentais e o papel das Normas Operacionais Básicas. Ciênc Saúde Coletiva 2001; 6:269-91.

5. Machado CV, Lima LD, Baptista TWF. Políticas de saúde no Brasil em tempos contraditórios: caminhos e tropeços na construção de um sistema universal. Cad Saúde Pública 2017; 33:e00129616.

6. Arretche M. A política da política de saúde no Brasil. In: Lima NT, Gerschman S, Edler FC, Suárez JM, organizadores. Saúde e democracia: história e perspectivas do SUS. Rio de Janeiro: Editora Fiocruz; 2005. p. 285-306. 
7. Lindelow M. A marca do SUS. http://www. worldbank.org/pt/news/opinion/2013/12/20/ brazil-sus-unified-public-healthcare-systemnew-study (acessado em 15/Mar/2018).

8. Coalizão Saúde. Coalizão Saúde Brasil: uma agenda para transformar o sistema de saúde, 2017. Disponível em: http://icos.org.br/ wp-content/uploads/2017/04/Relato\% CC\%81rioNet.pdf (acessado em 18/Mar/2018).

9. Filgueira ML. Hospitais privados aumentam leitos enquanto os públicos reduzem. Exame 2018; 1 fev. https://exame.abril.com.br/blog/ primeiro-lugar/hospitais-privados-aumentam -leitos-enquanto-os-publicos-reduzem/.

10. Mouffe C. El retorno de lo político: comunidad, ciudadanía, pluralismo, democracia radical. Barcelona: Ediciones Paidós Ibérica; 1999.

11. Nobre M. Teoria crítica: uma nova geração. Apresentação de dossiê. Novos Estudos CEBRAP 2012; 93:23-7.

12. Domingues JM. Vicissitudes e possibilidades da teoria crítica hoje. Sociologia \& Antropologia 2011; 1:71-89.

13. Braga JC. Saúde e Previdência Social. São Paulo: Editora Hucitec; 1981.

14. Oliveira JA, Teixeira SMF. (Im) Previdência Social: 60 anos de história da Previdência no Brasil. Petrópolis: Editora Vozes; 1986.

15. Tesouro Nacional. Gasto social do Governo Central 2002 a 2015. http://www.tesouro. fazenda.gov.br/documents/10180/318974/ Gasto+Social+Governo+Central/ (acessado em 10/Fev/2018).

16. Instituito Brasileiro de Geografia e Estatística. Conta-satélite de saúde: Brasil: 2010-2015. Rio de Janeiro: Instituito Brasileiro de Geografia e Estatística; 2017.

17. Coordenadoria de Auditorias Temáticas e Operacionais, Núcleos de Saúde, Tribunal de Contas do Estado do Rio de Janeiro. Contratação de serviços de saúde nos municípios do Estado do Rio de Janeiro. http://www.tce.rj.gov.br/docu ments/10192/33305601/Contrata\%C3\%A7\% C3\%A3o\%20de\%20servi\%C3\%A7 os\%20de\%20 sa\%C $3 \%$ BAde $\% 20$ nos $\% 20$ munic\%C $3 \%$ AD pios\%20do\%20Rio\%20Renata.ppt (acessado em 18/Mar/2018).

18. World Health Organization. Domestic general government health expenditure (GGHE-D) as percentage of current health expenditure (CHE) (\%). Data by country. http://apps.who.int/gho/data/node.main. GHEDGGHEDCHESHA2011?lang=en (acessado em 10/Fev/2018).
19. Agência Nacional de Saúde Suplementar. Mapa assistencial da saúde suplementar 2016. Rio de Janeiro: Agência Nacional de Saúde Suplementar; 2017.

20. Associação Nacional de Hospitais Privados. Revista Observatório Anahp 2016; 8. http:// anahp.com.br/produtos-anahp/observatorio/ observatorio-anahp-ingles-2016.

21. Carvalho LM. 1988: segredos da Constituinte. Rio de Janeiro: Edições Record; 2017.

22. Giovanella L, Almeida PF. Atenção primária integral e sistemas segmentados de saúde na América do Sul. Cad Saúde Pública 2017; 33 Suppl 2:e00118816.

23. Segatto C. Planos de saúde investem em médicos de família. Revista Época 2017; 18 set. https://epoca.globo.com/saude/noticia/ 2017/09/planos-de-saude-investem-emmedicos-de-familia.html.

24. Gusso GDF, Knupp D, Trindade, TG, Lermen Junior N, Poli Neto P. Bases para um novo sanitarismo. Rev Bras Med Fam Comunidade 2015; 10:1-10.

25. Coalizão Saúde. Proposta para o sistema de saúde brasileiro. http://icos.org.br/wp-con tent/uploads/2016/04/Coalizao_Brochura.pdf (acessado em 18/Mar/2018).

26. Associação da Indústria Farmacêutica de Pesquisa. Custos da saúde: fatos e interpretações. https://www.interfarma.org.br/public/fi les/biblioteca/custos-da-saude-fatos-e-inter pretacoes-interfarma1.pdf (acessado em 18/ Mar/2018).

27. Colluci C. Tamanho do SUS precisa ser revisto, diz novo ministro da Saúde. Folha de S. Paulo 2016; 17 mai. http://www1.folha.uol.com.br/ cotidiano/2016/05/1771901-tamanho-dosus-precisa-ser-revisto-diz-novo-ministro-dasaude.shtml.

28. Ministério da Saúde. Portaria no 1.482, de 4 de agosto de 2016. Institui grupo de trabalho para discutir projeto de Plano de Saúde Acessível. Diário Oficial da União 2016; 5 ago.

29. Ministério da Saúde. Portaria no 3.991, de 28 de dezembro de 2017. Habilita o Estado, Município ou Distrito Federal a receber recursos destinados aquisição de equipamentos e materiais permanentes para estabelecimentos de saúde. Diário Oficial da União 2017; 28 dez. 
30. Conselho de Defesa da Concorrência, Ministério da Justiça. Documento de trabalho 001/2016. Identificação do mercado geográfico relevante para os hospitais no Brasil. Brasília: Conselho de Defesa da Concorrência; Ministérioda Justiça; 2016.

31. Banco Nacional de Desenvolvimento Econômico e Social. Relatório de efetividade 20072014: a contribuição do BNDES para o desenvolvimento nacional. https://www.bndes.gov. $\mathrm{br} / \mathrm{wps} / \mathrm{wcm} / \mathrm{connect} / \mathrm{site} /$ relatorio_efetivida de_2007_2014 (acessado em 20/Mar/2018).

32. De Seta MH, Oliveira CVS, Pepe VLE. Proteção à saúde no Brasil: o Sistema Nacional de Vigilância Sanitária. Ciênc Saúde Coletiva 2017; 22:3225-34.

33. Câmara dos Deputados. Frentes parlamentares da 55a legislatura. http://www.camara.leg.br/ internet/deputado/frentes.asp (acessado em 23/Mar/2018).

34. Câmara dos Deputados. Requerimento no 3.708, de 08 de dezembro de 2015. Requer o Registro da Frente Parlamentar da Indústria Pública de Medicamentos. http://www.camara. leg.br/internet/deputado/Frente_Parlamentar/ 53670-integra.pdf (acessado em 23/Mar/2018)

35. Jardim L. O dono da ANS. O Globo 2017; 2 jun. https://blogs.oglobo.globo.com/lauro-jardim/ post/o-dono-da-ans.html.

36. Trindade N. Líder do Podemos quer a presidência da Funasa. Estadão 2017; 28 nov. http:// politica.estadao.com.br/blogs/coluna-do-est adao/lider-do-podemos-quer-a-presidenciada-funasa/.
37. Acervo Estadão. Estatização degrada a medicina brasileira. Edição Nacional. http://acervo. estadao.com.br/ (acessado em 11/Dez/2017).

38. Couto CG. Emendas constitucionais. In: Avritzer L, Anastasia F, organizadores. Reforma política no Brasil. Belo Horizonte: Editora da UFMG; 2006. p. 202-6.

39. Nobre M. Indeterminação e estabilidade: os 20 anos da Constituição Federal e as tarefas da pesquisa em direito. Novos Estudos CEBRAP 2008; 82:97-106.

40. Mello FC. O projeto de reconstrução nacional. http://www.biblioteca.presidencia.gov.br/ presidencia/ex-presidentes/fernando-collor/ discursos/discurso-de-posse/posse-collor.pdf/ view (acessado em 03/Abr/2017).

41. Cardoso FH. Discurso na abertura do Conselho Nacional de Saúde. http://www.biblioteca. presidencia.gov.br/presidencia/ex-presiden tes/fernando-henrique-cardoso/discursos/1o -mandato/1997/5-de-fevereiro-de-1997-dis curso-na-abertura-do-conselho-nacional-desaude/view (acessado em 30/Mar/2018).

42. Grün R. Financeirização de esquerda? Frutos inesperados no Brasil do século XXI. Tempo Social 2009; 21:153-84.

43. Streeck W. How will capitalism end? New Left Review 2014; 87:35-64.

44. Marx K. O 18 de brumário de Luís Bonaparte. São Paulo: Boitempo; 2011. (Coleção Marx-Engels). 


\section{Abstract}

This article describes changes in the public, nonprofit, and private components of the health care networks and health insurance and health plan companies in Brazil, based on the accumulated knowledge concerning the gains and obstacles in the Brazilian Unified National Health System (SUS) and differences between policies for democratization and democratizing processes. This central premise allowed analyzing praise versus criticism for the SUS and the contemporary nature of relations between the public and private sectors, drawing on secondary data from agencies in the Executive, Legislative, and Judiciary branches. The article concludes that the highly financialized private and private-charitable sectors imposed anti-democratic and anti-democratizing standards in the use of public funds. The article further concludes that although these sectors have not raised barriers to certain public policies for the expansion of access, they nevertheless prevent the development of the SUS according to the principles set out in the 1988 Constitution.

Unified Health System; Health Care; Health Policy

\section{Resumen}

Este trabajo ha considerado el acervo de conocimientos sobre avances e impases del Sistema Único de Salud (SUS), en él se detalla, según las diferencias entre políticas dirigidas a la democratización y procesos democratizantes, cambios en los componentes público, filantrópico y privado, que integran redes asistenciales y empresas de planes $y$ seguros de salud. Este hilo conductor permitió recabar afirmaciones elogiosas o peyorativas sobre el SUS, y el carácter contemporáneo de las relaciones entre lo público y lo privado, a partir de información secundaria de fuentes gubernamentales como: órganos de los poderes Ejecutivo, Legislativo y Judicial. Se concluye que el sector privado $y$ filantrópico-privado, eminentemente financierizados, impusieron patrones antidemocráticos $y$ antidemocratizantes para el uso de fondos públicos que, aunque no impongan obstáculos a determinadas políticas públicas de ampliación del acceso a la salud, impiden la construcción efectiva del SUS constitucional.

Sistema Único de Salud; Atención a la Salud; Politica de Salud 